\title{
Neuroprotective effects of resveratrol in Alzheimer disease pathology
}

\author{
Shraddha D. Rege ${ }^{1}$, Thangiah Geetha ${ }^{2}$, Gerald D. Griffin ${ }^{3}$, Tom L. Broderick ${ }^{4}$ and \\ Jeganathan Ramesh Babu ${ }^{1}$ * \\ 'Department of Nutrition, Dietetics, and Hospitality Management, Auburn University, Auburn, AL, USA \\ ${ }^{2}$ Department of Chemistry, Auburn University at Montgomery, Montgomery, AL, USA \\ ${ }^{3}$ Department of Biology, Tuskegee Institute, Tuskegee University, AL, USA \\ ${ }^{4}$ Laboratory of Diabetes and Exercise Metabolism, Department of Physiology, Midwestern University, Glendale, AZ, USA
}

\section{Edited by:}

George E. Barreto, Pontificia

Universidad Javeriana, Colombia

\section{Reviewed by:}

Nibaldo C. Inestrosa, Pontifical Catholic University of Chile, Chile Gloria Patricia Cardona Gomez, University of Antioquia, Colombia

\section{*Correspondence:}

Tom L. Broderick, Laboratory of Diabetes and Exercise Metabolism, Department of Physiology,

Midwestern University, Glendale, AZ 85308, USA

e-mail: tbrode@midwestern.edu; Jeganathan Ramesh Babu,

Department of Nutrition, Dietetics, and Hospitality Management, Auburn University, Auburn, AL 36849, USA, e-mail: jeganrb@auburn.edu

\begin{abstract}
Alzheimer's disease is a chronic neurodegenerative disorder characterized by a progressive loss of cognitive and behavioral abilities. Extracellular senile plaques and intracellular neurofibrillary tangles are hallmarks of $A D$. Researchers aim to analyze the molecular mechanisms underlying $A D$ pathogenesis; however, the therapeutic options available to treat this disease are inadequate. In the past few years, several studies have reported interesting insights about the neuroprotective properties of the polyphenolic compound resveratrol $(3,5,4$ '-trihydroxy-trans-stilbene) when used with in vitro and in vivo models of $A D$. The aim of this review is to focus on the neuroprotective and antioxidant effects of resveratrol on $A D$ and its multiple potential mechanisms of action. In addition, because the naturally occurring forms of resveratrol have a very limited half-life in plasma, a description of potential analogs aimed at increasing the bioavailability in plasma is also discussed.
\end{abstract}

Keywords: Alzheimer disease, beta-amyloid, oxidative stress, resveratrol, neuroprotection

\section{INTRODUCTION}

Resveratrol (3,5,4'-trihydroxy-trans-stilbene) is a naturally occurring polyphenolic compound, which belongs to the phytoalexin superfamily. This compound was first isolated from the roots of white hellebore (Veratrum grandiflorum O. LOES) and was named by Dr. Michio Takaoka in his thesis in 1940. The discovery of resveratrol by Dr. Takaoka was the prime step leading to establishing the scientific efficacy of the Chinese "material medica," a collection of traditional Asian medicines (Takaoka, 1940). In 1963, resveratrol was isolated from the roots of Polygonum cuspidatum, a traditional Chinese and Japanese medicine Ko-jo-kon (Nonomura et al., 1963). Resveratrol is present in skin and seeds of more than 70 different plant species, including grapes, berries, grains, tea, and peanuts (Soleas et al., 1997; Chen et al., 2002). In the presence of an enzyme resveratrol synthase, the phytochemical resveratrol is synthesized in response to environmental stress such as heavy metal ions, injury, fungal infection, or UV irradiation from coumaroyl CoA and malonyl CoA (Singh et al., 2013). It is synthesized in the pericarp of grape berries, epidermis of grape berry leaf, and in the stalks and kernels of the berries (Creasy and Coffee, 1988). It constitutes one of the primary components in

Abbreviations: AD, Alzheimer's disease; APP, amyloid precursor protein; BBB, blood-brain barrier; CHD, coronary heart disease; GST, glutathione $S$-transferase; NOS, nitrogen oxide synthase; ROS, reactive oxygen species; SAM, senescence accelerated mice; SOD, superoxide dismutase; TH, tyrosine hydrolase. red wine and is claimed to be an essential factor in the French Paradox, a term frequently used to summarize the apparently paradoxical epidemiological observation that French people have a relatively low incidence of CHD despite having a diet relatively rich in saturated fats (Liu et al., 2007; Sun et al., 2008). The level of resveratrol in plants reaches its peak approximately $24 \mathrm{~h}$ after stress exposure and subsides after $42-72 \mathrm{~h}$ due to the activation of stilbene oxidase (Soleas et al., 2001; Jeandet et al., 2002). Resveratrol belongs to a group of compounds called the stilbene family, which contain two aromatic rings joined by a methylene bridge. Stilbene synthase (STS), which belongs to a multigene family of the type 3 group of the polyketide synthase superfamily, is the enzyme that controls the production of resveratrol in plant tissues (Bais et al., 2000). Resveratrol exists in two geometric isomers with trans and cis configuration (Figure 1). Trans-resveratrol is considered to be a non-toxic potential stereoisomer and is widely known to possess the reported beneficial health effects (Orallo, 2006).

Indeed, resveratrol is also protective against oxidative stress, inflammation (Das and Das, 2007), and the development of cardiovascular diseases (Chen et al., 2002), diabetes (Venturini et al., 2010), neurodegenerative diseases (Vingtdeux et al., 2008), and cancer (Kris-Etherton et al., 2002). Resveratrol plays a prominent role in the prevention of neurodegenerative diseases such as $\mathrm{AD}$, Parkinson's disease, cerebral ischemia as well as Huntington's disease because resveratrol enters the blood stream after the 


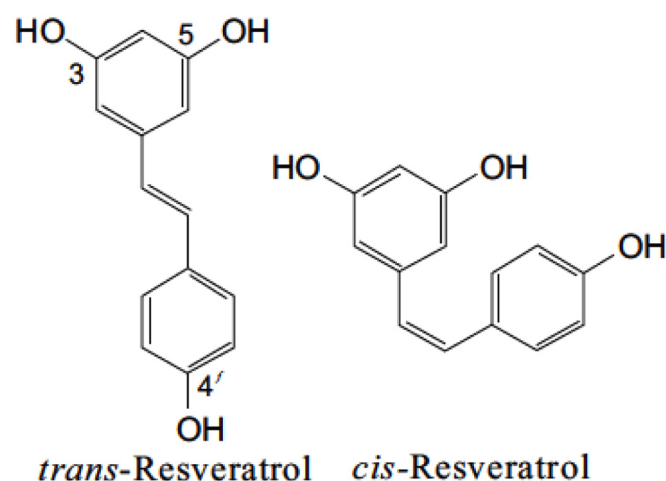

FIGURE 1 | Isomers of resveratrol. Chemical structures of trans and cis-resveratrol.

formation of glucuronide conjugates and can readily pass through the BBB; Baur and Sinclair, 2006). Resveratrol $(10-100 \mu \mathrm{M})$ is reported to exert neuroprotective effects in several studies (Richard et al., 2011). In this review, we discuss the several beneficial effects of resveratrol and newly designed resveratrol analogs in $\mathrm{AD}$ and its potential to promote human health.

\section{METABOLISM AND BIOAVAILABILITY OF RESVERATROL}

Resveratrol is rapidly absorbed and metabolized on oral administration to form glucuronide and sulfate conjugates, which are excreted in urine (Vingtdeux etal., 2008). In humans, the primary metabolite of resveratrol is trans-resveratrol-3-Oglucuronide, whereas in mice and rats, trans-resveratrol-3-O glucuronide and trans-resveratrol-3-sulfate are the primary metabolites, respectively (Yu etal., 2002). Several studies conducted on the bioavailability of resveratrol indicate that poor absorption and rapid metabolism of resveratrol and its metabolites like glucuronides and sulfates results in low oral bioavailability of resveratrol (Wenzel and Somoza, 2005). Studies by Walle (2011) have shown the oral absorption rate of resveratrol to be $70-75 \%$ with respect to the urinary excretion of the total metabolites after radiolabelled doses. Plasma concentrations of resveratrol ranged from 1 to $5 \mathrm{ng} / \mathrm{ml}$ on administration of $25 \mathrm{mg}$ resveratrol (Almeida et al., 2009), a concentration commonly used in experimental studies and associated with various beneficial effects on cardiovascular, endothelial, and neurologic function (Zhang et al., 2009, 2010; Clark et al., 2012; Rege et al., 2013). Administration of higher doses up to $5 \mathrm{~g}$ led to a proportional increase in the plasma resveratrol to about $500 \mathrm{ng} / \mathrm{ml}$ (Boocock et al., 2007). Despite its poor bioavailability and rapid disposal, resveratrol does indeed accumulate in tissues, including brain, even after acute or short-term treatment. Acute administration of resveratrol by oral gavage using a low dose of $80 \mu \mathrm{g} / \mathrm{kg}$ results in significant accumulation in brain within 4 h (Bertelli et al., 1999). Short term treatment using a concentration of $40 \mu \mathrm{g} / \mathrm{kg}$ by the same route of administration for a period of 15 days also increases resveratrol content in the brain (Bertelli et al., 1999). Resveratrol is known to have several beneficial effects in brain but its poor bioavailability or the matrix within which it is contained in the dietary media are issues of major concern for resveratrol delivery (Goldberg et al., 2003; Mohar and Malik, 2012).

\section{BIOAVAILABILITY OF RESVERATROL AND ITS ANALOGS}

The $\mathrm{BBB}$ is a highly selective permeable endothelial cell layer connected by tight junctions, sequestering the CNS tissue from vasculature. This barrier is permeable to the flow of water, some gases, nutrients, and lipid soluble molecules through passive diffusion. In addition, the BBB prevents entry of many neurotoxins by P-glycoprotein-mediated active transport. Polyphenols are accessible and enter the brain only if they cross the BBB (Vauzour, 2012). Based on in vitro studies, the permeability of polyphenols through the $\mathrm{BBB}$ depends on several factors such as the lipophilic state of the compound and increased capability of brain uptake by less polar polyphenols or metabolites (such as O-methylated derivatives; Youdim et al., 2003). Resveratrol being a lipophilic compound can readily cross the $\mathrm{BBB}$ via transmembrane diffusion (Lin et al., 2010). Further, to effectively penetrate the $\mathrm{BBB}$, molecules must be below $500 \mathrm{Da}$ in molecular weight (Banks, 2009). Resveratrol, with its molecular weight of $228 \mathrm{Da}$ (Amri etal., 2012) and lipid soluble properties, should easily cross the BBB. Faria et al. (2010) demonstrated that similar sized flavonoids found in red wine such as quercetin and catechin can easily penetrate membranes in RBE- 4 cells, an immortalized cell line of rat cerebral capillary endothelial cells.

However, resveratrol's low bioavailability originating from its poor water solubility and resulting from its short biological halflife, labile properties, rapid metabolism and clearance limits the efficacious concentrations of resveratrol to accumulate in plasma and target tissues (Walle, 2011; Cho et al., 2014). Therefore, several drug delivery systems are designed to improve these inherent biologic limitations of resveratrol, such as increasing its solubility and preventing resveratrol from rapid degradation while preserving its biological activity. Approaches aimed at controlling its release from the gastrointestinal tract to enhance its bioavailability are also considered (Sessa et al., 2011; Augustin et al., 2013). At present, several drug delivery systems for enhancing the bioavailability and solubility of resveratrol have been developed such as encapsulation in liposomal formulations, the design of resveratrol-protein complexes to favor resveratrol binding to protein, use of cyclodextrin complexes and solid lipid nanoparticles for enhanced matrix-based delivery, pectinate delivery systems, and chitosan microspheres (Augustin et al., 2013). In agreement with this novel delivery systems, recent evidence has shown that administration of $5 \mathrm{mg} / \mathrm{kg}$ of resveratrol in loaded-lipid core nanocapsules every $12 \mathrm{~h}$ intraperitoneally for 14 days is effective against the neurotoxicity induced by intracerebroventricular injection of A $\beta 1-42$ in rats (Frozza et al., 2013). Also, the use of more potent analogs of resveratrol such as SRT501 (Howells et al., 2011) and resveratrol in combination therapy with piperine, a natural product obtained from black pepper, have proved to be efficient methods of enhancing its bioavailability (Johnson et al., 2011).

Recently, Csiszár et al. (2014) reported that encapsulation of resveratrol into novel fusogenic liposomes is more efficient than conventional liposomes. This approach enhances the delivery of polyphenol resveratrol into aged cells leading to the activation 
of cellular Nrf2-mediated antioxidant defense systems (Csiszár et al., 2014). Furthermore, the use of polyethylene glycol (PEG) derivatives presents several advantageous features for delivery. PEG as an oral vehicle material is a non-toxic polymer, has high water solubility, is both non-teratogenic and non-immunogenic, and exhibits antigenic properties. Two types of amino acid PEGylated resveratrol conjugates developed to date demonstrate increased solubility of resveratrol up to $900 \mathrm{mg} \mathrm{mL} \mathrm{m}^{-1}$, clearly highlighting the potential of PEGylated compounds as an effective system for improving the solubility and bioavailability of resveratrol (Zhang et al., 2014).

Resveratrol exhibits good absorption rates but low bioavailability. An oral dose of $25 \mathrm{mg}$ results in less than $5 \mu \mathrm{g} / \mathrm{mL}$ in the serum following absorption through the gastrointestinal tract, corresponding to approximately a 1000 -fold decrease in bioavailability. A 125 -fold lower dose of $0.2 \mathrm{mg}$, yet in the milligram amount, injected intravenously results in plasma levels in the low nanogram range (16.4-30.7 $\mathrm{ng} / \mathrm{mL}$ ) (Walle et al., 2004) This rapid clearance is due to the reduction in the amount of free resveratrol from conjugation by sulfation and glucuronidation via P 450 enzymes. Albumin and lipoproteins serve as the major carriers for resveratrol in plasma (Delmas et al., 2011). After ingestion of resveratrol, conjugation produces resveratrol- $O$ glucuronide and resveratrol- $C$-glucuronide (Cottart et al., 2010). More than $90 \%$ of free resveratrol is bound to human plasma lipoproteins and $50 \%$ of the plasma trans-resveratrol-3-sulfate, trans-resveratrol-disulfates and the novel trans-resveratrol-C/Odiglucuronides are non-covalently bound to proteins as reported by Burkon and Somoza (2008). Evidence shows that resveratrol undergoes enterohepatic metabolism in both rats and humans (Timmers et al., 2012). After uptake by enterocytes, resveratrol is metabolized to sulfate and glucuronide conjugates, which may be deconjugated by gut microflora, reabsorbed, or excreted in the feces. Thus, the enterohepatic circulation decreases the amount of free compound reaching the target tissues. Hence, a small fraction of the ingested resveratrol reaches the tissues (Timmers et al., 2012). In a brain ischemic model, results suggest that resveratrol enters the blood stream after its formation to glucuronide conjugates and could thereby cross the BBB (Wang et al., 2002). To overcome the potential limitations of low bioavailability and metabolism, a therapeutic approach in developing congeners and analogs of resveratrol should be undertaken. Modification of resveratrol's chemical structure by altering the number and position of the hydroxyl groups, intramolecular hydrogen bonding, double bonds, and stereoisomerism is crucial for improving the efficacy and enhancing the bioavailability. Stilbene monomers include methyl and methoxy group subsitutions, and variations in cis and trans configurations (Cottart et al., 2010). Systemic exposure to pterostilbene, a dimethyl derivative of resveratrol, resulted in significantly higher plasma levels when compared with resveratrol following administration at equimolar doses in male rats over 14 consecutive days. Treatment with pterostilbene also produced a sevenfold rise in its oral bioavailability than the parent resveratrol (Kapetanovic et al., 2011). A recent study by Greer et al. (2014) aimed at improving the bioavailability of trans resveratrol (tRes) by modifying its structure to reduce glucuronidation revealed three new stilbene derivatives. These derivatives of tRes with hydroxyl, aromatic nitro and carboxyl substituents to create NI-ST-05, DNR1 , and NI-12a, respectively, were less prone to glucuronidation, suggesting that tRes analogs improve bioavailability and could be potentially developed as alternate therapeutics (Greer et al., 2014). Several other resveratrol analogs such as hexahydroxystilbene (M8), galic acid, digalloyl resveratrol exert free radical scavenging properties and anti-carcinogenic effects (Szekeres et al., 2010). Another naturally occurring resveratrol analog, 3,5,4' -trimethoxytrans stilbene, had greater plasma exposure, a longer half-life and lower clearance rates in rats (Lin and Ho, 2009). Several studies have indicated resveratrol to be a potent activator of SIRT 1. Sirtuins are $\mathrm{NAD}^{+}$-dependent class III histone/protein deacetylase (HDAC) enzymes. SIRT 1 deacetylates nucleosomal histones at specific residues by translocating from cytoplasm to nucleus and contributes to transcriptional silencing of telomeres and life span expansion (Pallàs et al., 2013). Recent studies demonstrate that both natural and synthetic sirtuin activating compounds (STACs) promotes allosteric SIRT 1 activation by binding of STACs to a conserved N-terminal domain in SIRT1. Recently sirtuins have gained considerable importance due to its key role in the calorie restriction (CR) response and as possible therapeutic drug targets. Amongst all the naturally occurring activators of SIRT 1, resveratrol is considered to be the most effective SIRT 1 activator. However, synthetic STACs have been documented to possess more potency, solubility and bioavailability as compared to natural STACs. The first synthetic STACs such as SRT1460, SRT1720, and SRT2183 were derivatives of an imidazothiazole scaffold and chemically different from the polyphenol resveratrol. Like resveratrol, SRT1720 compound was shown to activate SIRT1 by lowering the $K_{\mathrm{m}}$ for the substrate peptide. The third generation STACs derived from benzimidazole and urea-based scaffolds were more potent than resveratrol itself (Hubbard and Sinclair, 2014)

\section{RESVERATROL ANALOGS IN THE TREATMENT OF AD}

Currently, several studies have reported various polyphenols exhibiting neuroprotective effects both in vivo and in vitro. Resveratrol and its derivatives have gained a prime importance amongst all these polyphenols due to their neuroprotective properties.

Piceatannol, a monohydroxylated derivative of resveratrol that differs by an additional hydroxyl group in $3^{\prime}$ of benzene ring, has shown to exhibit neuroprotective effects against beta-amyloid induced neural cell death by blocking $A \beta$-induced accumulation of ROS (Kim et al., 2007b). Pterostilbene has shown to be a potent modulator of cognition and cellular oxidative stress associated with AD (Chang et al., 2012). In addition to monomers, several dimers and oligomers have been developed. Two new stilbene dimers, scirpusin A with an additional hydroxyl group, and $\varepsilon$ viniferin glucoside, with a glucose moiety, demonstrated a robust inhibition of fibril accumulation, thereby could be used as efficient fibril inhibitors in the treatment of AD (Rivière et al., 2010).

$\mathrm{Lu}$ and colleagues designed a novel series of resveratrol derivatives serving as multi-target agents in the treatment of AD. Amongst the synthesized compounds, 5d (E)-2-((4- $(3,5-$ Dimethoxystyryl) phenylamino) methyl)-4-(dimethylamino) phenol and 10d (E)-5-(4-(5-(Dimethylamino)-2-hydroxybenzylamino) styryl)-benzene-1,3-diol exerted significant inhibition of $A \beta$ aggregation, metal-chelating ability, disintegration of highly 
structured $\mathrm{A} \beta$ fibrils and $\mathrm{Cu}(\mathrm{II})$-induced $\mathrm{A} \beta$ aggregation, antioxidant activity and low neurotoxicity. Moreover, compound 5d could also cross the BBB in vitro and doses up to $2000 \mathrm{mg} / \mathrm{kg}$ were not associated with any signs of toxicity in mice (Lu et al., 2013). Lu and colleagues previously reported a series of stilbene derivatives based on the structure of resveratrol in which compound 71 (E)-5-(4-(isopropylamino)styryl)benzene-13 -diol exerted potent $\beta$-amyloid aggregation inhibition activity (Lu et al., 2012). Novel synthetic compounds such as STACs confer remarkable health benefits in various animal models. SRT3025 is one such STAC, which penetrates the BBB; mimics the effects of $\mathrm{CR}$ on the brain and further reduces neurodegeneration (Hubbard and Sinclair, 2014). In conclusion, various resveratrol analogs developed with improved bioavailability possess neuroprotective properties and could be further used as novel multifunctional drugs in the treatment of AD.

\section{RESVERATROL CONTENT IN WINE AND PLANTS}

Resveratrol occurs as free resveratrol and as $3 \beta$-glucoside, a derivative of resveratrol both in grapes and wine (Vrhovšek etal., 1995; Romero-Pérez etal., 1996). Concentrations of resveratrol in grape species range from 50 to $400 \mu \mathrm{g} / \mathrm{g}$ fresh weight in the leaves and fresh grape skin contains around 50-100 $\mu \mathrm{g}$ of resveratrol per gram (Jeandet et al., 1991). In grape juices, the concentration of free resveratrol is low as compared to cis- and trans-piceid derivatives of resveratrol (Romero-Pérez etal., 1999). The levels of resveratrol vary from 3 to $15 \mu \mathrm{g} / \mathrm{L}$ and 690 to $14,500 \mu \mathrm{g} / \mathrm{L}$ in grape juices (Romero-Pérez et al., 1999).

The concentration of resveratrol in wine varies considerably and is also largely dependent on the grape cultivar, geographic conditions and exposure to fungal infections. Typically, the total concentration of resveratrol in red wine is between 0.2 and $5.8 \mathrm{mg} / \mathrm{L}$ while white wine contains approximately $0.68 \mathrm{mg} / \mathrm{L}$. Red wines have six times higher concentrations of trans-resveratrol than white wines while white wines contain high levels of cisresveratrol. Red wine is extracted without removing the grape skin, whereas white wine is fermented only after removal of the skin (Prasad, 2012). Other sources of common foods containing resveratrol include dark chocolate, various berries, soy, and raw or boiled peanuts.

\section{ANTIOXIDANT PROPERTIES OF RESVERATROL IN AD}

Resveratrol exhibits strong antioxidant properties as shown by in vitro and in vivo studies (Sönmez et al., 2007; Venturini et al., 2010). Oxidative stress occurs due to an imbalance between pro-oxidant and antioxidant activities in the body leading to the excessive production of ROS, free radicals and peroxides (Barnham et al., 2004). Brain tissue is more susceptible to oxidative stress due to its greater rate of oxygen consumption, high content of peroxidizable fatty acids, less regenerative capability, and low amounts of antioxidants. Thus, free radicals seem to play a crucial role in the process of brain aging (Floyd, 1999; Honda et al., 2004; Romano et al., 2010). AD is an age-related disorder, most often diagnosed in individuals over 65 years of age and hence aging is strongly implicated in the pathogenesis of this disease (Jayasena et al., 2013).
Alzheimer's disease is characterized by neuritic plaques composed of insoluble deposits amyloid $\beta$ peptide (Vingtdeux et al., 2008), neurofibrillary tangles and synaptic loss together, which leads to a gradual decline in cognitive function (Kolarova et al., 2012). The hallmarks of $A D$ are the presence of neurofibrillary tangles and $\mathrm{A} \beta$ senile plaques in the cortex and the hippocampus, respectively (Selkoe, 2002). Hyper-phosphorylation and abnormal deposition of tau protein results in the formation of neurofibrillary tangles whereas $A \beta$ senile plaques contains deposits of $\beta$-amyloid (A $\beta$ ) peptide (Golde et al., 1992). Beta-amyloid is a 39-43 amino acid peptide fragment derived from the sequential proteolytic cleavage of the APP by the enzymes beta $(\beta)$ and gamma $(\gamma)-$ secretase (Huang et al., 2011). In 2000, around 25 million people were diagnosed with $\mathrm{AD}$ worldwide, and this number is expected to increase to 114 million by 2050 (Wimo et al., 2003). Early age onset $\mathrm{AD}$ is a form of $\mathrm{AD}$ diagnosed in the age group younger than 65 years. A small portion of all early age onset AD population consists of familial $\mathrm{AD}$ cases whereas a large portion of late onset $\mathrm{AD}$ patients are sporadic $\mathrm{AD}$ cases, a form of $\mathrm{AD}$ diagnosed in the population older than 65 years (Piaceri et al., 2013). In familial AD patients, mutations are observed in the APP, presenilin 1 (PSEN1), and presenilin 2 (PSEN2) genes. Though the specific causes of sporadic $\mathrm{AD}$ are unknown, many genetic and environmental factors contribute to the development of sporadic AD (Selkoe, 2001). The key factors contributing to the pathogenesis of both familial and sporadic forms of $\mathrm{AD}$ are $\mathrm{A} \beta$ peptides (Selkoe, 2001; Selkoe et al, 2004). Thus, the therapeutic goal in the treatment of $\mathrm{AD}$ serves to target both $\mathrm{A} \beta$ production and amyloid fibril aggregation (Roberson and Mucke, 2006). Oxidative stress caused by an excessive production of ROS in the brain has been considered as the underlying cause for the pathogenesis of a number of neurodegenerative disorders. An increase in levels of ROS, reactive nitrogen species, or some malfunction of the cellular antioxidant systems can damage protein and membrane poly unsaturated fatty acids, causing lipid peroxidation and further leads to loss of membrane integrity and increased permeability to $\mathrm{Ca}^{2+}$ in the plasma membrane (Floyd, 1999; Sun et al., 2008; Rege et al., 2013). Moreover, it causes injury to neural membranes and ultimately memory impairment (Sun et al., 2010). Several in vivo and in vitro studies have reported that ROS increases $A \beta$ production and $A \beta$ induces oxidative stress, which may together accelerate the progression of AD (Murakami et al., 2005; Tabner et al., 2005). However, plant derived dietary antioxidants can be regarded as potential useful targets for the prevention of neuronal damage in neurodegenerative disorders.

Resveratrol suppresses oxygen free radical formation by inhibiting pro-oxidative genes such as nicotinamide adenine dinucleotide phosphate oxidase and myeloperoxidase, and inducing various antioxidant enzymes like SOD, catalase, thioredoxin and glutathione peroxide (GSH-Px; Wang etal., 2012; Carrizzo et al., 2013), while lowering the activity of enzymes involved in the development of oxidative stress (Carrizzo et al., 2013; Figure 2). Thus resveratrol is a direct scavenger of free radicals production in tissues. It is interesting that resveratrol has proven to be effective in suppressing iNOS production, which is involved in the $\mathrm{A} \beta$-induced lipid peroxidation and heme oxygenase- 1 (HO1) downregulation, thereby protecting the rats from $A \beta$-induced 


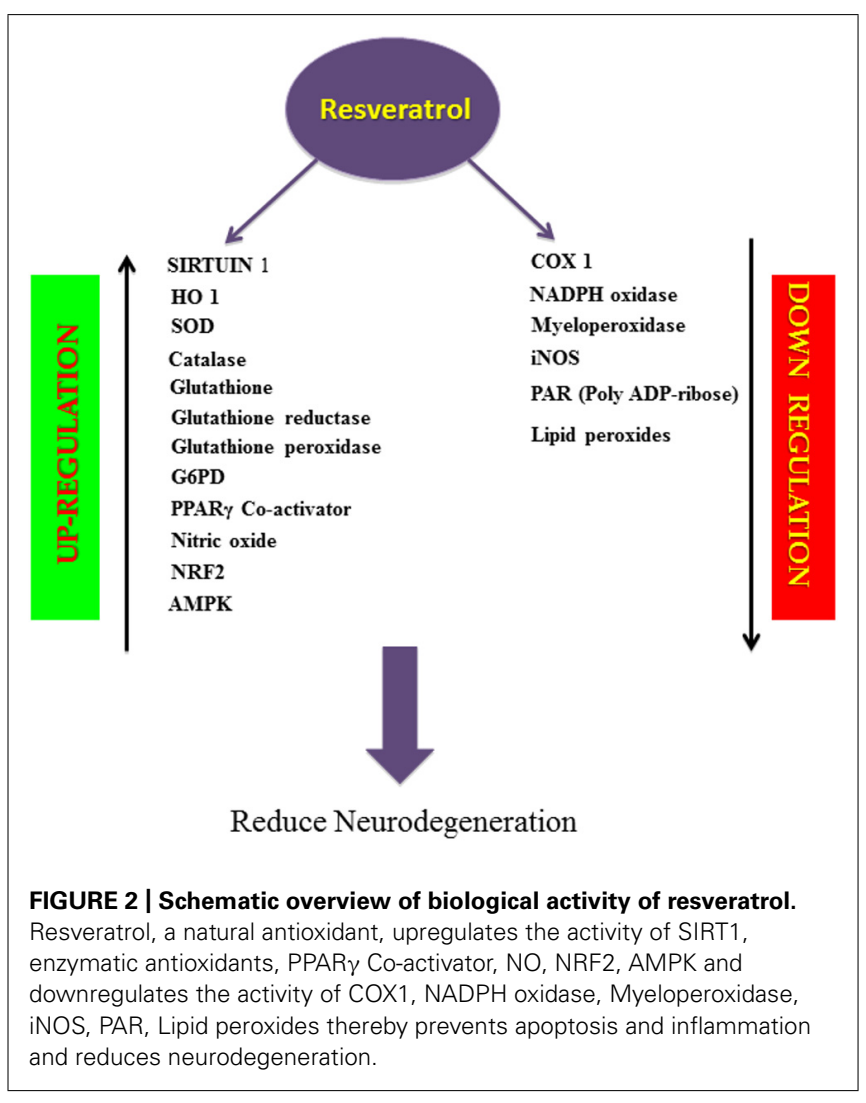

neurotoxicity (Table 1A; Huang et al., 2011; Figure 2). One of the major pathological features in $\mathrm{AD}$ is cerebral metal ion imbalance. Ions of copper, iron, zinc, and aluminum act as key cofactors in various neuronal functions, including cellular respiration, cellular redox homeostasis, nerve transmission, oxygen transport and functioning of the channels. Dysregulation in the metal ion balance plays a key role in driving neurodegeneration, which is likely to impact cellular function and ultimately neuronal survival. Decreased levels of copper lead to ROS generation and neuronal inflammation in association with $\mathrm{A} \beta$ deposition. Resveratrol administration with a high affinity copper chelator may attenuate copper imbalance and ROS production. Similarly, resveratrol can prevent the accumulation of free iron and iron mediated ROS generation and can also counteract the iron-induced mitochondrial dysfunction by suppressing GSK3 $\beta$ activity. Excessive accumulation of zinc and aluminum also promotes ROS production, increases neuroinflammation eventually leading to AD. However, resveratrol has not shown to have direct effects on the levels of zinc but can prevent further development of zinc-related ill effects. Moreover, resveratrol seems to cause an ameliorative change in aluminum induced neurotoxicity (Granzotto and Zatta, 2014). Findings of Granzatto et al. suggest that resveratrol acts as a neuroprotectant against $\mathrm{A} \beta$ as well as against $\mathrm{A} \beta$-metal complexes. In addition, resveratrol exerts ROS scavenging properties and reduces toxicity against $A \beta-F e, A \beta-C u$, and $\mathrm{A} \beta-\mathrm{Zn}$, but fails to completely block $\mathrm{A} \beta-\mathrm{Al}$ and $\mathrm{A} \beta-\mathrm{Cu}$ toxicity (Table 1B; Granzotto and Zatta, 2011). A substantial amount of research has attributed this polyphenol for its anti-antioxidant and cytoprotective actions in oxidative stress-induced brain pathologies. Consequently, resveratrol appears to improve glial, oxidative and inflammatory responses by enhancing the expression of HO- 1 and extracellular GSH content in $\mathrm{H}_{2} \mathrm{O}_{2}$-induced C6 cells (Quincozes-Santos et al., 2013). Moreover, resveratrol also protected PC12 cells against amyloid-induced cytotoxicity, cell death, and intracellular ROS accumulation and also suppressed beta-amyloid-induced activation of NF-KB in PC12 cells (Jang and Surh, 2003). Another key enzyme known as Poly (ADP-ribose) polymerase-1 (PARP-1) plays a key role in the regulation of $\mathrm{A} \beta$ precursor protein metabolism processing. Studies have reported that over-activation of PARP-1 due to oxidative stress leads to an accumulation of the novel signaling molecule poly-ADP-ribose (PAR), which induces neuronal cell death associated with AD pathogenesis (Strosznajder et al., 2012; Figure 2). Findings by Lee et al. indicated resveratrol reduced PARP-1 cleavage and protected SH-SY5Y neuroblastoma cells from apoptosis (Lee et al., 2007). Resveratrol being a robust activator of SIRT1 has shown to possess anti-amyloidogenic activity through the activation of SIRT 1 in the brains of Tg2576 mice and protects the cells against oxidative damage (Kelsey et al., 2010; Figure 2) Furthermore, resveratrol prolongs the synthesis of $A \beta$ in neuronal cultures expressing APP and reduces $A \beta$ production by stimulating SIRT 1 activity (Tang and Chua, 2008). Also, resveratrol protects neocortical neurons cultured from the senescence-accelerated mouse strain SAMP8 against increased susceptibility to oxidative damage via SIRT 1 activation (Table 1C; Cristòfol et al., 2012). Thus, SIRT 1 appears to be a promising new avenue for therapeutic intervention in age related $\mathrm{AD}$.

\section{BENEFICIAL EFFECTS OF RESVERATROL ON NEURONAL INFLAMMATION IN AD}

Neuronal inflammation promotes the pathogenesis of several chronic neurodegenerative diseases, including AD. Various reports show that the inflammatory responses occurring in central nervous system such as activation of microglia, astrocytes, lymphocytes and macrophages triggers numerous pro- and antiinflammatory mediators such as ROS, NOS, cytokines, and various neurotransmitters (Moore and O'Banion, 2002). Activation of microglia releases highly ROS such as hydroxyl radicals, superoxide and per oxy radicals, hydroxyl peroxide, and thereby causes oxidation of proteins, lipid peroxidation, and DNA fragmentation. These processes eventually lead to neuronal inflammation and cell death (Liu and Hong, 2003). Amyloid $\beta$ peptides, the major component of amyloid plaques interact with various Tolllike receptors (TLRs) such as TLR4 and can trigger microglial activation. Anti-inflammatory action of resveratrol has shown to prevent lipopolysaccharide (LPS, a TLR4 ligand)-induced activation of murine RAW 264.7 macrophages and microglial BV-2 cells. It also prevented proinflammatory effect of $A \beta$ on macrophages by inhibiting activation of STAT 1 and STAT3 and

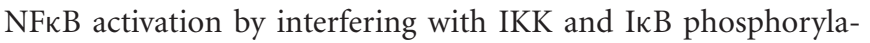
tion (Capiralla et al., 2012). In addition, oral administration of resveratrol in a mouse model of cerebral amyloid deposition significantly reduced microglial activation related to amyloid deposition (Table 1D; Capiralla etal., 2012). Since NF-кB signaling is involved in $\mathrm{A} \beta$-induced neuronal cell death, another link between 


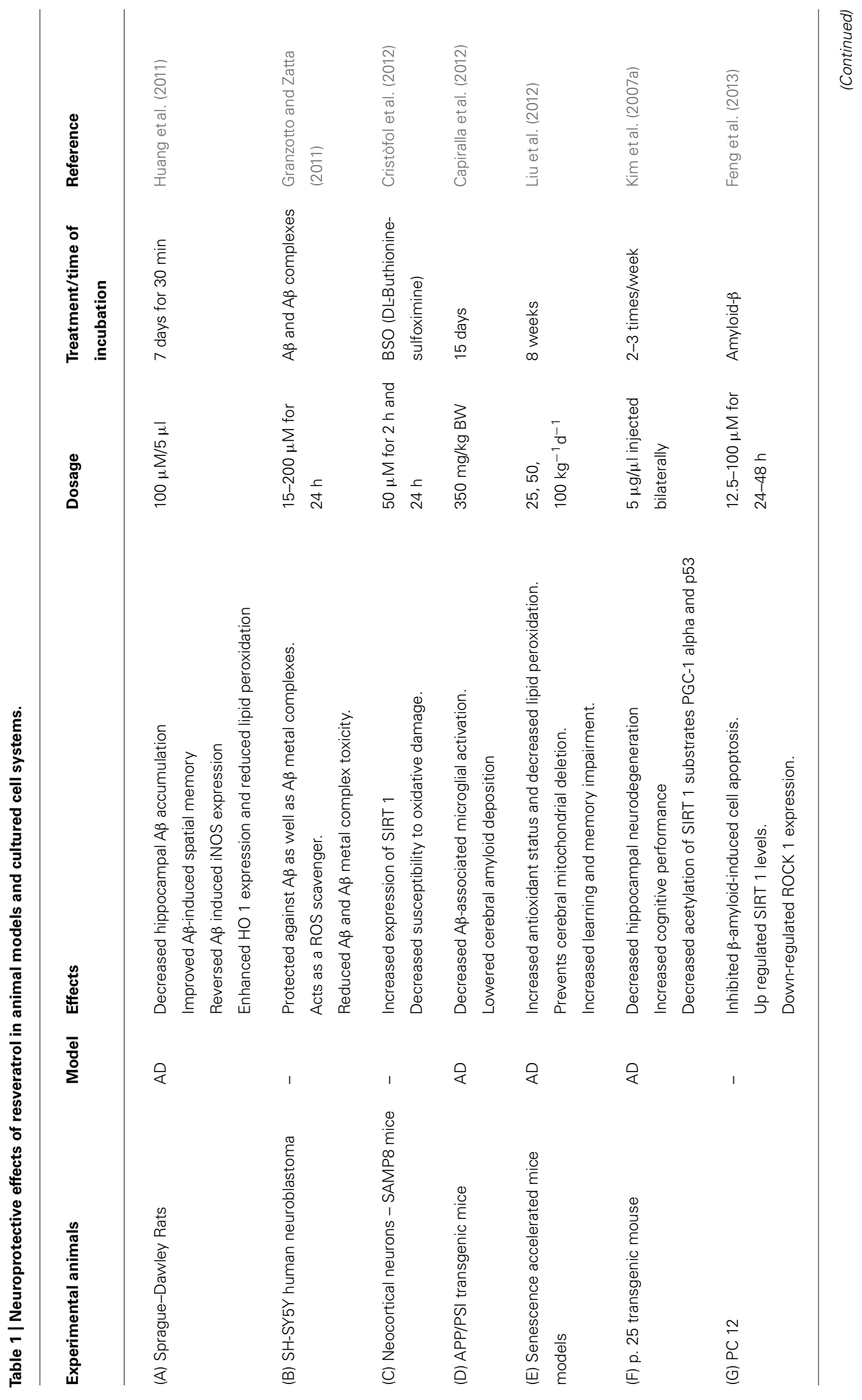




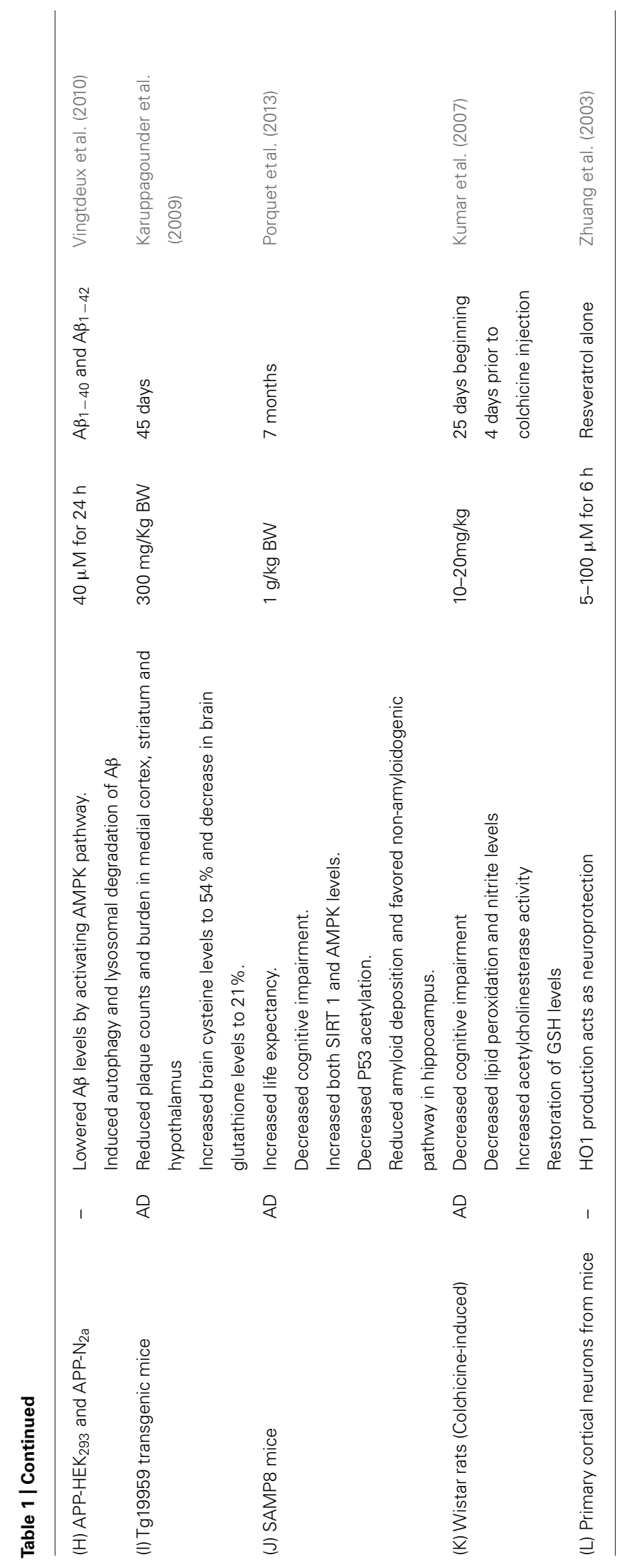


$\mathrm{AD}$ and neuroprotective action of resveratrol is its potential to decrease the expression of iNOS, prostaglandin E2 (PGE2),

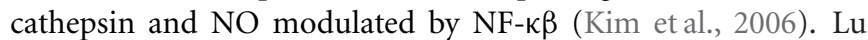
and colleagues reported that resveratrol attenuates LPS-stimulated $\mathrm{NF}-\kappa \mathrm{B}$ activation in murine primary microglia and astrocytes and LPS-induced inflammatory responses could be modulated by different potencies of resveratrol (Lu et al., 2010). Studies have shown that astrocytes in brain have both positive and negative effects on the central nervous system. They serve as a source of nutrients to neurons and aid in the maintenance of extracellular ion balance as well as in the clearance and degradation of $\mathrm{A} \beta$ (Wyss-Coray et al., 2003; Lee et al., 2010). Astrocytes also secrete prostaglandins, interleukins, leukotrienes, thromboxanes, and form bunches around A $\beta$ deposits (Sidoryk-Wegrzynowicz et al., 2011). A study by Simao et al. showed resveratrol pretreatment $(30 \mathrm{mg} / \mathrm{kg})$ significantly reduced NF- $\kappa \mathrm{B}$ and JNK activation, and decreased the global cerebral ischemia-induced astroglial and microglial activation and iNOS and COX-2 regulation (Simão et al., 2012). Resveratrol reduces the concentration of 8 -iso-prostaglandin F2 $\alpha$, an indicator of free radical production in LPS-activated rat microglial cells, and is considered to be involved in the downregulation of neuroinflammatory responses (Candelario-Jalil et al., 2007). Resveratrol treatment decreased lipid peroxidation, thereby causing an upregulation in the antioxidant status in the senescence-accelerated mouse model. It also prevented cerebral mitochondrial deletion and decreased the impairment in learning and memory (Table 1E; Liu et al., 2012).

\section{ANTI-AMYLOIDOGENIC EFFECTS OF RESVERATROL}

Resveratrol exhibits its neuroprotective effects in the inhibition of $\beta$-amyloid production and aggregation and in the destabilization of the $A \beta$ fibrils (Ono et al., 2006). Resveratrol also decreases the accumulation of $A \beta$ in cell cultures and lowers $A \beta$ secretion from different cell lines. Since it has no effect on the A $\beta$ producing enzymes, $\beta$ and $\gamma$ secretases, it does not suppress $A \beta$ production but promotes proteolytic clearance of $A \beta$ through a mechanism that implicates a proteasome and not NEP (neprilysin) ECE-1 and ECE-2 (endothelin converting enzyme 1 and 2) or IDE (insulin degrading enzyme) (Marambaud et al., 2005). Chronic administration of resveratrol proved to be effective in protecting animal models of $\mathrm{AD}$ from $\mathrm{A} \beta$-induced neuronal loss, cell death, accumulations of lipid peroxide products, inhibition of hippocampal iNOS production, and the elevation of $\mathrm{HO}-1$ expression. In accordance with this, resveratrol showed recovery from $A \beta$-induced spatial memory impairment in the animal models of AD (Huang et al., 2011). Further, consumption of red wine significantly reduces the impairment of spatial memory function and A $\beta$ neuropathology in Tg2576 mice (Wang et al., 2006). Another study by Lu et al. suggested that administration of resveratrol lowered MPTP-induced deterioration of motor coordination and neuronal loss caused by excessive production of free radicals (Lu et al., 2008). A marked reduction in neurodegeneration in the hippocampus was observed on administration of intracerebroventricular injection of resveratrol, which was caused by a decrease in the acetylation of SIRT1 substances such as peroxisome proliferator-activated receptor gamma co-activator and p53 (Kim et al., 2007a). This eventually prevented learning deficit in the p25 transgenic mouse model of AD (Table 1F; Kim et al., 2007a). Moreover, an in vitro model of PC12 cells using $A \beta_{25-35}$ provided new compelling evidence on the protective effect of resveratrol against $A \beta$ induced neurotoxicity. Resveratrol protected PC12 cells and inhibited A $\beta$-induced cell apoptosis through the upregulation of SIRT 1 expression and downregulation of Rho-associated kinase 1 (ROCK 1). Thus, anti-apoptopic actions of resveratrol were partially mediated through the SIRT1ROCK 1 pathway (Table 1G; Feng et al., 2013). Resveratrol is also found to exert its neuroprotective actions via the activation of key metabolic sensor proteins, such as the AMP-activated protein kinase (AMPK; Figure 2). Resveratrol induced AMPK activation results in the inhibition of AMPK target mTOR (mammalian target of rapamycin), initiation of autophagy and promotion of lysosomal clearance of A $\beta$ (Vingtdeux et al., 2010). Studies indicate that resveratrol lowers $A \beta$ accumulation in the cortex due to activation of AMPK signaling by enhancing cytosolic $\mathrm{Ca}^{2+}$ levels and CaMKK $\beta$-dependent phosphorylation of AMPK in primary neuronal cultures (Table 1H; Vingtdeux etal., 2010). It has also been shown to decrease the formation of plaques in specific regions of brain thereby slowing down the process of neurodegeneration (Table 1I; Karuppagounder et al., 2009). A recent study by Porquet and colleagues reported that dietary resveratrol supplementation at the dose of $1 \mathrm{~g} / \mathrm{kg}$ body weight to SAMP8 mice, an age-related model of $\mathrm{AD}$, activates AMPK pathways, prosurvival routes such as SIRT1 and reduces amyloid accumulation, tau hyperphosphorylation and cognitive impairment (Table 1J; Porquet et al., 2013). Resveratrol at dosages of 10 and $20 \mathrm{mg} / \mathrm{kg}$ manifests a neuroprotective action against colchicine-induced cognitive impairment and oxidative damage in Wistar rats (Table 1K; Kumar et al., 2007). Furthermore, resveratrol treatment has also shown to suppress the levels of NOS and the expression of COX-2 in beta-amyloid treated C6 glioma cells (Kim etal., 2006). Another key player in the regulation of cellular antioxidant mechanism is nuclear factor erythroid 2-related factor 2 (Nrf2). Nrf2 serves as a chief regulator of cellular resistance to oxidants and genes encoding antioxidant proteins such as $\mathrm{HO}-1$, NAD (P) H-quinone oxidoreductase, GST and glutathione synthetase (GSS; Scapagnini et al., 2011). Under normal unstressed conditions, Nrf2 is anchored by Keap 1 (Kelch-like ECH-associating protein 1) in the cytoplasm, which causes polyubiquitination and proteasome mediated degradation. It has also been shown to induce $\mathrm{HO} 1$ via $\mathrm{Nrf} 2$ and $\mathrm{PI} 3 \mathrm{~K} / \mathrm{AKT}$ pathways and thereby reduce ROS induced oxidative damage in PC 12 cells (Chen et al., 2005). Resveratrol is known to promote HO-1 expression through the activation of Nrf2 in primary neuronal cultures (Table 1L; Zhuang et al., 2003; Figure 2). Thus, Nrf2 serves as a promising target for resveratrol in the prevention/treatment of certain neurodegenerative diseases.

\section{CONCLUSION}

Resveratrol has been recognized as a potential therapeutic agent for treating wide array of health conditions/diseases such as inflammation, pain, tissue injury, diabetes, and cancer. However, emerging evidence focuses strongly on its potential beneficial effects against several neurodegenerative diseases. In this review, 
we discussed the antioxidant properties as well as neuroprotective effects of resveratrol in the pathogenesis of $\mathrm{AD}$. For example, in $\mathrm{AD}$, resveratrol promotes clearance of $A \beta$ peptides, anti-amyloidogenic cleavage of APP, its ability to reduce oxidative stress and neuronal cell death. Consequently, it is plausible to recommend resveratrol as one of the promising tools in the development of drug therapy for AD. Moreover, it is non-toxic, cost effective, and widely available. However, the efficacy and utility of resveratrol also depends upon its solubility and bioavailability. Therefore, future research on the design and synthesis of novel analogs needs to be conducted to address these issues.

\section{ACKNOWLEDGMENTS}

This work was supported by the Auburn University Intramural Grants program (AU-IGP) and Alabama Agricultural Experimental Station, Hatch/Multistate Funding Program to Jeganathan Ramesh Babu, School of Sciences Dean's initiative grants to Thangiah Geetha and Malone-Zallen Graduate Research Fellowship to Shraddha D. Rege.

\section{REFERENCES}

Almeida, L., Vaz-da Silva, M., Falcão, A., Soares, E., Costa, R., Loureiro, A. I., et al. (2009). Pharmacokinetic and safety profile of trans-resveratrol in a rising multiple-dose study in healthy volunteers. Mol. Nutr. Food Res. 53(Suppl. 1), S7-S15. doi: 10.1002/mnfr.200800177

Amri, A., Chaumeil, J. C., Sfar, S., and Charrueau, C. (2012). Administration of resveratrol: what formulation solutions to bioavailability limitations? J. Control. Release 158, 182-193. doi: 10.1016/j.jconrel.2011.09.083

Augustin, M. A., Sanguansri, L., and Lockett, T. (2013). Nano- and microencapsulated systems for enhancing the delivery of resveratrol. Ann. N. Y. Acad. Sci. 1290, 107-112. doi: 10.1111/nyas. 12130

Bais, A. J., Murphy, P. J., and Dry, I. B. (2000). The molecular regulation of stilbene phytoalexin biosynthesis in Vitis vinifera during grape berry development. Funct. Plant Biol. 27, 425-433. doi: 10.1071/PP00007

Banks, W. A. (2009). Characteristics of compounds that cross the blood-brain barrier. BMC Neurol. 9:S3. doi: 10.1186/1471-2377-9-S1-S3

Barnham, K. J., Masters, C. L., and Bush, A. I. (2004). Neurodegenerative diseases and oxidative stress. Nat. Rev. Drug Discov. 3, 205-214. doi: 10.1038/nrd1330

Baur, J. A., and Sinclair, D. A. (2006). Therapeutic potential of resveratrol: the in vivo evidence. Nat. Rev. Drug Discov. 5, 493-506. doi: 10.1038/nrd2060

Bertelli, A. A., Ferrara, F., Diana, G., Fulgenzi, A., Corsi, M., Ponti, W., et al. (1999). Resveratrol, a natural stilbene in grapes and wine, enhances intraphagocytosis in human promonocytes: a co-factor in antiinflammatory and anticancer chemopreventive activity. Int. J. Tissue React. 21, 93-104.

Boocock, D. J., Patel, K. R., Faust, G. E. S., Normolle, D. P., Marczylo, T. H., Crowell, J. A., et al. (2007). Quantitation of trans-resveratrol and detection of its metabolites in human plasma and urine by high performance liquid chromatography. J. Chromatogr. B Anal. Technol. Biomed. Life Sci. 848, 182-187. doi: 10.1016/j.jchromb.2006.10.017

Burkon, A., and Somoza, V. (2008). Quantification of free and proteinbound trans-resveratrol metabolites and identification of trans-resveratrol$\mathrm{C} / \mathrm{O}$-conjugated diglucuronides - two novel resveratrol metabolites in human plasma. Mol. Nutr. Food Res. 52, 549-557. doi: 10.1002/mnfr. 200700290

Candelario-Jalil, E., de Oliveira, A. C. P., Gräf, S., Bhatia, H. S., Hüll, M., Muñoz, E., et al. (2007). Resveratrol potently reduces prostaglandin E2 production and free radical formation in lipopolysaccharide-activated primary rat microglia. $J$. Neuroinflamm. 4, 25. doi: 10.1186/1742-2094-4-25

Capiralla, H., Vingtdeux, V., Zhao, H., Sankowski, R., Al-Abed, Y., Davies, P., etal. (2012). Resveratrol mitigates lipopolysaccharide- and A $\beta$ mediated microglial inflammation by inhibiting the TLR4/NF- $\mathrm{B} / \mathrm{STAT}$ signaling cascade. J. Neurochem. 120, 461-472. doi: 10.1111/j.1471-4159.2011. 07594.x

Carrizzo, A., Forte, M., Damato, A., Trimarco, V., Salzano, F., Bartolo, M., et al. (2013). Antioxidant effects of resveratrol in cardiovascular, cerebral and metabolic diseases. Food Chem. Toxicol. 61, 215-226. doi: 10.1016/j.fct.2013. 07.021

Chang, J., Rimando, A., Pallas, M., Camins, A., Porquet, D., Reeves, J., et al. (2012). Low-dose pterostilbene, but not resveratrol, is a potent neuromodulator in aging and Alzheimer's disease. Neurobiol. Aging 33, 2062-2071. doi: 10.1016/j.neurobiolaging.2011.08.015

Chen, C.-Y., Jang, J.-H., Li, M.-H., and Surh, Y.-J. (2005). Resveratrol upregulates heme oxygenase-1 expression via activation of NF-E2-related factor 2 in PC12 cells. Biochem. Biophys. Res. Commun. 331, 993-1000. doi: 10.1016/j.bbrc.2005.03.237

Chen, R.-S., Wu, P.-L., and Chiou, R. Y.-Y. (2002). Peanut roots as a source of resveratrol. J. Agric. Food Chem. 50, 1665-1667. doi: 10.1021/jf011134e

Cho, A. R., Chun, Y. G., Kim, B. K., and Park, D. J. (2014). Preparation of chitosan-TPP microspheres as resveratrol carriers. J. Food Sci. 79, E568-576. doi: 10.1111/1750-3841.12395

Clark, D., Tuor, U. I., Thompson, R., Institoris, A., Kulynych, A., Zhang, X., et al. (2012). Protection against recurrent stroke with resveratrol: endothelial protection. PLoS ONE 7:e47792. doi: 10.1371/journal.pone.0047792

Cottart, C.-H., Nivet-Antoine, V., Laguillier-Morizot, C., and Beaudeux, J.-L. (2010). Resveratrol bioavailability and toxicity in humans. Mol. Nutr. Food Res. 54, 7-16. doi: 10.1002/mnfr.200900437

Creasy, L. L., and Coffee, M. (1988). Phytoalexin production potential of grape berries. J. Am. Soc. Horticult. Sci. 113, 230-234.

Cristòfol, R., Porquet, D., Corpas, R., Coto-Montes, A., Serret, J., Camins, A., et al. (2012). Neurons from senescence-accelerated SAMP8 mice are protected against frailty by the sirtuin 1 promoting agents melatonin and resveratrol. J. Pineal Res. 52, 271-281. doi: 10.1111/j.1600-079X.2011.00939.x

Csiszár, A., Csiszar, A., Pinto, J. T., Gautam, T., Kleusch, C., Hoffmann, B., et al. (2014). Resveratrol encapsulated in novel fusogenic liposomes activates nrf2 and attenuates oxidative stress in cerebromicrovascular endothelial cells from aged rats. J. Gerontol. A Biol. Sci. Med. Sci. 1-11. doi: 10.1093/gerona/glu029 [Epub ahead of print].

Das, S., and Das, D. K. (2007). Anti-inflammatory responses of resveratrol. Inflamm. Allergy Drug Targets 6, 168-173. doi: 10.2174/1871528077 81696464

Delmas, D., Aires, V., Limagne, E., Dutartre, P., Mazué, F., Ghiringhelli, F., et al. (2011). Transport, stability, and biological activity of resveratrol. Ann. N. Y. Acad. Sci. 1215, 48-59. doi: 10.1111/j.1749-6632.2010.05871.x

Faria, A., Pestana, D., Teixeira, D., Azevedo, J., De Freitas, V., Mateus, N., et al. (2010). Flavonoid transport across RBE4 cells: a blood-brain barrier model. Cell. Mol. Biol. Lett. 15, 234-241. doi: 10.2478/s11658-010-0006-4

Feng, X., Liang, N., Zhu, D., Gao, Q., Peng, L., Dong, H., et al. (2013). Resveratrol inhibits $\beta$-amyloid-induced neuronal apoptosis through regulation of SIRT1-ROCK1 signaling pathway. PLOS ONE 8:e59888. doi: 10.1371/journal.pone.0059888

Floyd, R. A. (1999). Antioxidants, oxidative stress, and degenerative neurological disorders. Proc. Soc. Exp. Biol. Med. 222, 236-245. doi: 10.1046/j.15251373.1999.d01-140.x

Frozza, R. L., Bernardi, A., Hoppe, J. B., Meneghetti, A. B., Matté, A., Battastini, A. M. O., et al. (2013). Neuroprotective effects of resveratrol against $A \beta$ administration in rats are improved by lipid-core nanocapsules. Mol. Neurobiol. 47, 1066-1080. doi: 10.1007/s12035-013-8401-2

Goldberg, D. M., Yan, J., and Soleas, G. J. (2003). Absorption of three wine-related polyphenols in three different matrices by healthy subjects. Clin. Biochem. 36, 79-87. doi: 10.1016/S0009-9120(02)00397-1

Golde, T. E., Estus, S., Younkin, L. H., Selkoe, D. J., and Younkin, S. G. (1992). Processing of the amyloid protein precursor to potentially amyloidogenic derivatives. Science 255, 728-730. doi: 10.1126/science.1738847

Granzotto, A., and Zatta, P. (2011). Resveratrol acts not through anti-aggregative pathways but mainly via its scavenging properties against $\mathrm{A} \beta$ and $\mathrm{A} \beta$-metal complexes toxicity. PLoS ONE 6:e21565. doi: 10.1371/journal.pone.0021565

Granzotto, A., and Zatta, P. (2014). Resveratrol and Alzheimer's disease: message in a bottle on red wine and cognition. Front. Aging Neurosci. 6:95. doi: 10.3389/fnagi.2014.00095

Greer, A. K., Madadi, N. R., Bratton, S. M., Eddy, S. D., Mazerska, Z., Hendrickson, H. P., et al. (2014). Novel resveratrol-based substrates for human hepatic, renal, and intestinal UDP-glucuronosyltransferases. Chem. Res. Toxicol. 27, 536-545. doi: $10.1021 /$ tx400408x 
Honda, K., Casadesus, G., Petersen, R. B., Perry, G., and Smith, M. A. (2004). Oxidative stress and redox-active iron in Alzheimer's disease. Ann. N. Y. Acad. Sci. 1012, 179-182. doi: 10.1196/annals.1306.015

Howells, L. M., Berry, D. P., Elliott, P. J., Jacobson, E. W., Hoffmann, E., Hegarty, B., et al. (2011). Phase I randomized, double-blind pilot study of micronized resveratrol (SRT501) in patients with hepatic metastases-safety, pharmacokinetics, and pharmacodynamics. Cancer Prev. Res. (Phila) 4, 1419-1425. doi: 10.1158/1940-6207.CAPR-11-0148

Huang, T.-C., Lu, K.-T., Wo, Y.-Y. P., Wu, Y.-J., and Yang, Y.-L. (2011). Resveratrol protects rats from $A \beta$-induced neurotoxicity by the reduction of iNOS expression and lipid peroxidation. PLOS ONE 6:e29102. doi: 10.1371/journal.pone.0029102

Hubbard, B. P., and Sinclair, D. A. (2014). Small molecule SIRT1 activators for the treatment of aging and age-related diseases. Trends Pharmacol. Sci. 35, 146-154. doi: 10.1016/j.tips.2013.12.004 -s36

Jang, J.-H., and Surh, Y.-J. (2003). Protective effect of resveratrol on beta-amyloidinduced oxidative PC12 cell death. Free Radic. Biol. Med. 34, 1100-1110. doi: 10.1016/S0891-5849(03)00062-5

Jayasena, T., Poljak, A., Smythe, G., Braidy, N., Münch, G., and Sachdev, P. (2013). The role of polyphenols in the modulation of sirtuins and other pathways involved in Alzheimer's disease. Ageing Res. Rev. 12, 867-883. doi: 10.1016/j.arr.2013.06.003

Jeandet, P., Bessis, R., and Gautheron, B. (1991). The production of resveratrol (3.5.4' - trihydroxystilbene) by grape berries in different developmental stages. Am. J. Enol. Vitic. 42, 41-46.

Jeandet, P., Douillet-Breuil, A.-C., Bessis, R., Debord, S., Sbaghi, M., and Adrian, M. (2002). Phytoalexins from the Vitaceae: biosynthesis, phytoalexin gene expression in transgenic plants, antifungal activity, and metabolism. J. Agric. Food Chem. 50, 2731-2741. doi: 10.1021/jf011429s

Johnson, J. J., Nihal, M., Siddiqui, I. A., Scarlett, C. O., Bailey, H. H., Mukhtar, H., et al. (2011). Enhancing the bioavailability of resveratrol by combining it with piperine. Mol. Nutr. Food Res. 55, 1169-1176. doi: 10.1002/mnfr. 201100117

Kapetanovic, I. M., Muzzio, M., Huang, Z., Thompson, T. N., and McCormick, D. L. (2011). Pharmacokinetics, oral bioavailability, and metabolic profile of resveratro and its dimethylether analog, pterostilbene, in rats. Cancer Chemother. Pharmacol. 68, 593-601. doi: 10.1007/s00280-010-1525-4

Karuppagounder, S. S., Pinto, J. T., Xu, H., Chen, H.-L., Beal, M. F., and Gibson, G. E. (2009). Dietary supplementation with resveratrol reduces plaque pathology in a transgenic model of Alzheimer's disease. Neurochem. Int. 54, 111-118. doi: 10.1016/j.neuint.2008.10.008

Kelsey, N. A., Wilkins, H. M., and Linseman, D. A. (2010). Nutraceutical antioxidants as novel neuroprotective agents. Mol. Basel Switz. 15, 7792-7814. doi: 10.3390/molecules15117792

Kim, D., Nguyen, M. D., Dobbin, M. M., Fischer, A., Sananbenesi, F., Rodgers, J. T., et al. (2007a). SIRT1 deacetylase protects against neurodegeneration in models for Alzheimer's disease and amyotrophic lateral sclerosis. EMBO J. 26, 3169-3179. doi: $10.1038 /$ sj.emboj.7601758

Kim, H. J., Lee, K. W., and Lee, H. J. (2007b). Protective effects of piceatannol against beta-amyloid-induced neuronal cell death. Ann. N. Y. Acad. Sci. 1095, 473-482. doi: 10.1196/annals.1397.051

Kim, Y. A., Lim, S.-Y., Rhee, S.-H., Park, K. Y., Kim, C.-H., Choi, B. T., et al. (2006). Resveratrol inhibits inducible nitric oxide synthase and cyclooxygenase-2 expression in beta-amyloid-treated C6 glioma cells. Int. J. Mol. Med. 17, 10691075.

Kolarova, M., García-Sierra, F., Bartos, A., Ricny, J., and Ripova, D. (2012). Structure and pathology of tau protein in Alzheimer disease. Int. J. Alzheimers Dis. 2012, 731526. doi: $10.1155 / 2012 / 731526$

Kris-Etherton, P. M., Hecker, K. D., Bonanome, A., Coval, S. M., Binkoski, A. E., Hilpert, K. F., et al. (2002). Bioactive compounds in foods: their role in the prevention of cardiovascular disease and cancer. Am. J. Med. 113(Suppl. 9B), 71S-88S. doi: 10.1016/S0002-9343(01)00995-0

Kumar, A., Naidu, P. S., Seghal, N., and Padi, S. S. V. (2007). Neuroprotective effects of resveratrol against intracerebroventricular colchicine-induced cognitive impairment and oxidative stress in rats. Pharmacology 79, 17-26. doi: 10.1159/000097511

Lee, M. K., Kang, S. J., Poncz, M., Song, K.-J., and Park, K. S. (2007). Resveratrol protects SH-SY5Y neuroblastoma cells from apoptosis induced by dopamine. Exp. Mol. Med. 39, 376-384. doi: 10.1038/emm.2007.42
Lee, Y.-J., Han, S. B., Nam, S.-Y., Oh, K.-W., and Hong, J. T. (2010). Inflammation and Alzheimer's disease. Arch. Pharm. Res. 33, 1539-1556. doi: 10.1007/s12272010-1006-7

Lin, H.-S., and Ho, P. C. (2009). A rapid HPLC method for the quantification of 3,5,4'-trimethoxy-trans-stilbene (TMS) in rat plasma and its application in pharmacokinetic study. J. Pharm. Biomed. Anal. 49, 387-392. doi: 10.1016/j.jpba.2008.10.042

Lin, Y.-L., Chang, H.-C., Chen, T.-L., Chang, J.-H., Chiu, W.-T., Lin, J.-W., et al. (2010). Resveratrol protects against oxidized LDL-induced breakage of the blood-brain barrier by lessening disruption of tight junctions and apoptotic insults to mouse cerebrovascular endothelial cells. J. Nutr. 140, 2187-2192. doi: 10.3945/jn.110.123505

Liu, B., and Hong, J.-S. (2003). Role of microglia in inflammationmediated neurodegenerative diseases: mechanisms and strategies for therapeutic intervention. J. Pharmacol. Exp. Ther. 304, 1-7. doi: 10.1124/jpet.102. 035048

Liu, B., Zhang, X., Zhang, W., and Zhen, H. (2007). New enlightenment of French Paradox: resveratrol's potential for cancer chemoprevention and anti-cancer therapy. Cancer Biol. Ther. 6, 1833-1836. doi: 10.4161/cbt.6. 12.5161

Liu, G.-S., Zhang, Z.-S., Yang, B., and He, W. (2012). Resveratrol attenuates oxidative damage and ameliorates cognitive impairment in the brain of senescence-accelerated mice. Life Sci. 91, 872-877. doi: 10.1016/j.lfs.2012.08.033

Lu, C., Guo, Y., Li, J., Yao, M., Liao, Q., Xie, Z., et al. (2012). Design, synthesis, and evaluation of resveratrol derivatives as Aß1-42 aggregation inhibitors, antioxidants, and neuroprotective agents. Bioorg. Med. Chem. Lett. 22, 7683-7687. doi: 10.1016/j.bmcl.2012.09.105

Lu, C., Guo, Y., Yan, J., Luo, Z., Luo, H.-B., Yan, M., et al. (2013). Design, synthesis, and evaluation of multitarget-directed resveratrol derivatives for the treatment of Alzheimer's disease. J. Med. Chem. 56, 5843-5859. doi: 10.1021/ jm400567s

Lu, K.-T., Ko, M.-C., Chen, B.-Y., Huang, J.-C., Hsieh, C.-W., Lee, M.-C., et al. (2008). Neuroprotective effects of resveratrol on MPTP-induced neuron loss mediated by free radical scavenging. J. Agric. Food Chem. 56, 6910-6913. doi: $10.1021 /$ jf8007212

Lu, X., Ma, L., Ruan, L., Kong, Y., Mou, H., Zhang, Z., et al. (2010). Resveratrol differentially modulates inflammatory responses of microglia and astrocytes. J. Neuroinflamm. 7, 46. doi: 10.1186/1742-2094-7-46

Marambaud, P., Zhao, H., and Davies, P. (2005). Resveratrol promotes clearance of Alzheimer's disease amyloid-beta peptides. J. Biol. Chem. 280, 37377-37382. doi: 10.1074/jbc.M508246200

Mohar, D. S., and Malik, S. (2012). The sirtuin system: the holy grail of resveratrol? J. Clin. Exp. Cardiol. 3, 216. doi: 10.4172/2155-9880.1000216

Moore, A. H., and O'Banion, M. K. (2002). Neuroinflammation and antiinflammatory therapy for Alzheimer's disease. Adv. Drug Deliv. Rev. 54, 1627-1656. doi: 10.1016/S0169-409X(02)00162-X

Murakami, K., Irie, K., Ohigashi, H., Hara, H., Nagao, M., Shimizu, T., et al. (2005). Formation and stabilization model of the 42-mer Abeta radical: implications for the long-lasting oxidative stress in Alzheimer's disease. J. Am. Chem. Soc. 127, 15168-15174. doi: 10.1021/ja054041c

Nonomura, S., Kanagawa, H., and Makimoto, A. (1963). [Chemical constituents of polygonaceous plants. i. studies on the components of ko-j o-kon. (polygonum cuspidatum sieb. et zucc.)]. Yakugaku Zasshi 83, 988-990.

Ono, K., Naiki, H., and Yamada, M. (2006). The development of preventives and therapeutics for Alzheimer's disease that inhibit the formation of beta-amyloid fibrils (fAbeta), as well as destabilize preformed fAbeta. Curr. Pharm. Des. 12, 4357-4375. doi: 10.2174/138161206778793010

Orallo, F. (2006). Comparative studies of the antioxidant effects of cis- and trans-resveratrol. Curr. Med. Chem. 13, 87-98. doi: 10.2174/0929867067 75197962

Pallàs, M., Porquet, D., Vicente, A., and Sanfeliu, C. (2013). Resveratrol: new avenues for a natural compound in neuroprotection. Curr. Pharm. Des. 19, 6726-6731. doi: 10.2174/1381612811319380005

Piaceri, I., Nacmias, B., and Sorbi, S. (2013). Genetics of familial and sporadic Alzheimer's disease. Front. Biosci. 5:167-177.

Porquet, D., Casadesús, G., Bayod, S., Vicente, A., Canudas, A. M., Vilaplana, J., et al. (2013). Dietary resveratrol prevents Alzheimer's markers and increases life span in SAMP8. Age (Dordr.) 35, 1851-1865. doi: 10.1007/s11357-012-9489-4 
Prasad, K. (2012). Resveratrol, wine, and atherosclerosis. Int. J. Angiol. 21, 7-18. doi: 10.1055/s-0032-1306417

Quincozes-Santos, A., Bobermin, L. D., Latini, A., Wajner, M., Souza, D. O., Gonçalves, C.-A., et al. (2013). Resveratrol protects C6 astrocyte cell line against hydrogen peroxide-induced oxidative stress through heme oxygenase 1. PLoS ONE 8:e64372. doi: 10.1371/journal.pone.0064372

Rege, S. D., Kumar, S., Wilson, D. N., Tamura, L., Geetha, T., Mathews, S. T., et al. (2013). Resveratrol protects the brain of obese mice from oxidative damage. Oxid. Med. Cell. Longev. 2013, 419092. doi: 10.1155/2013/419092

Richard, T., Pawlus, A. D., Iglésias, M.-L., Pedrot, E., Waffo-Teguo, P., Mérillon, J.-M., etal. (2011). Neuroprotective properties of resveratrol and derivatives. Ann. N. Y. Acad. Sci. 1215, 103-108. doi: 10.1111/j.1749-6632.2010. 05865.x

Rivière, C., Papastamoulis, Y., Fortin, P.-Y., Delchier, N., Andriamanarivo, S., Waffo-Teguo, P., et al. (2010). New stilbene dimers against amyloid fibril formation. Bioorg. Med. Chem. Lett. 20, 3441-3443. doi: 10.1016/j.bmcl.2009. 09.074

Roberson, E. D., and Mucke, L. (2006). 100 years and counting: prospects for defeating Alzheimer's disease. Science 314, 781-784. doi: 10.1126/science. 1132813

Romano, A. D., Serviddio, G., de Matthaeis, A., Bellanti, F., and Vendemiale, G. (2010). Oxidative stress and aging. J. Nephrol. 23(Suppl. 15), S29-S36.

Romero-Pérez, A. I., Lamuela-Raventós, R. M., Waterhouse, A. L., and de la TorreBoronat. M. C. (1996). Levels of cis- and trans-Resveratrol and Their Glucosides in White and Rosé Vitis vinifera Wines from Spain. J. Agric. Food Chem. 44, 2124-2128. doi: 10.1021/jf9507654

Romero-Pérez, A. I., Ibern-Gómez, M., Lamuela-Raventós, R. M., and de La TorreBoronat, M. C. (1999). Piceid, the major resveratrol derivative in grape juices. J. Agric. Food Chem. 47, 1533-1536. doi: 10.1021/jf981024g

Scapagnini, G., Vasto, S., Sonya, V., Abraham, N. G., Nader, A. G., Caruso, C., et al. (2011). Modulation of Nrf2/ARE pathway by food polyphenols: a nutritional neuroprotective strategy for cognitive and neurodegenerative disorders. Mol. Neurobiol. 44, 192-201. doi: 10.1007/s12035-011-8181-5

Selkoe, D. J. (2001). Alzheimer's disease results from the cerebral accumulation and cytotoxicity of amyloid beta-protein. J. Alzheimers Dis. 3, 75-80.

Selkoe, D. J. (2002). Deciphering the genesis and fate of amyloid beta-protein yields novel therapies for Alzheimer disease. J. Clin. Invest. 110, 1375-1381. doi: 10.1172/JCI16783

Selkoe, D. J., American College of Physicians, and American Physiological Society (2004). Alzheimer disease: mechanistic understanding predicts novel therapies. Ann. Intern. Med. 140, 627-638. doi: 10.7326/0003-4819-140-8-20040420000010

Sessa, M., Tsao, R., Liu, R., Ferrari, G., and Donsì, F. (2011). Evaluation of the stability and antioxidant activity of nanoencapsulated resveratrol during in vitro digestion. J. Agric. Food Chem. 59, 12352-12360. doi: 10.1021/jf2031346

Sidoryk-Wegrzynowicz, M., Wegrzynowicz, M., Lee, E., Bowman, A. B., and Aschner, M. (2011). Role of astrocytes in brain function and disease. Toxicol. Pathol. 39, 115-123. doi: 10.1177/0192623310385254

Simão, F., Matté, A., Pagnussat, A. S., Netto, C. A., and Salbego, C. G. (2012). Resveratrol preconditioning modulates inflammatory response in the rat hippocampus following global cerebral ischemia. Neurochem. Int. 61, 659-665. doi: 10.1016/j.neuint.2012.06.009

Singh, C. K., Kumar, A., Lavoie, H. A., Dipette, D. J., and Singh, U. S. (2013). Diabetic complications in pregnancy: is resveratrol a solution? Exp. Biol. Med. 238, 482-490. doi: 10.1177/1535370212473704

Soleas, G. J., Diamandis, E. P., and Goldberg, D. M. (2001). The world of resveratrol. Adv. Exp. Med. Biol. 492, 159-182. doi: 10.1007/978-1-46151283-7_13

Soleas, G. J., Diamandis, E. P., and Goldberg, D. M. (1997). Wine as a biological fluid: history, production, and role in disease prevention. J. Clin. Lab. Anal. 11, 287-313. doi: 10.1002/(SICI)1098-2825(1997)11:5<287::AID-JCLA6>3.0.CO;2-4

Sönmez, U., Sönmez, A., Erbil, G., Tekmen, I., and Baykara, B. (2007). Neuroprotective effects of resveratrol against traumatic brain injury in immature rats. Neurosci. Lett. 420, 133-137. doi: 10.1016/j.neulet.2007. 04.070.

Strosznajder, J. B., Czapski, G. A., Adamczyk, A., and Strosznajder, R. P. (2012). Poly(ADP-ribose) polymerase-1 in amyloid beta toxicity and Alzheimer's disease. Mol. Neurobiol. 46, 78-84. doi: 10.1007/s12035012-8258-9
Sun, A. Y., Wang, Q., Simonyi, A., and Sun, G. Y. (2008). Botanical phenolics and brain health. Neuromolecular Med. 10, 259-274. doi: 10.1007/s12017-008-8052-Z Sun, A. Y., Wang, Q., Simonyi, A., and Sun, G. Y. (2010). Resveratrol as a therapeutic agent for neurodegenerative diseases. Mol. Neurobiol. 41, 375-383. doi: 10.1007/s12035-010-8111-y

Szekeres, T., Fritzer-Szekeres, M., Saiko, P., and Jäger, W. (2010). Resveratrol and resveratrol analogues - structure-activity relationship. Pharm. Res. 27, 10421048. doi: 10.1007/s11095-010-0090-1

Tabner, B. J., El-Agnaf, O. M. A., Turnbull, S., German, M. J., Paleologou, K. E., Hayashi, Y., et al. (2005). Hydrogen peroxide is generated during the very early stages of aggregation of the amyloid peptides implicated in Alzheimer disease and familial British dementia. J. Biol. Chem. 280, 35789-35792. doi: 10.1074/jbc.C500238200

Takaoka, M. (1940). The phenolic substances of white hellebore (Veratrum Grandiflorum Loes. Fill). V. Nippon Kagaku Kaishi 61, 1067-1069. doi: 10.1246/nikkashi1921.61.1067

Tang, B. L., and Chua, C. E. L. (2008). SIRT1 and neuronal diseases. Mol. Aspects Med. 29, 187-200. doi: 10.1016/j.mam.2007. 02.001

Timmers, S., Auwerx, J., and Schrauwen, P. (2012). The journey of resveratrol from yeast to human. Aging 4, 146-158.

Vauzour, D. (2012). Dietary polyphenols as modulators of brain functions: biological actions and molecular mechanisms underpinning their beneficial effects. Oxid. Med. Cell. Longev. 2012, e914273. doi: 10.1155/2012/ 914273

Venturini, C. D., Merlo, S., Souto, A. A., Fernandes, Mda. C., Gomez, R., and Rhoden, C. R. (2010). Resveratrol and red wine function as antioxidants in the nervous system without cellular proliferative effects during experimental diabetes. Oxid. Med. Cell. Longev. 3, 434-441. doi: 10.4161/oxim.3.6.14741

Vingtdeux, V., Dreses-Werringloer, U., Zhao, H., Davies, P., and Marambaud, P. (2008). Therapeutic potential of resveratrol in Alzheimer's disease. BMCNeurosci. 9(Suppl. 2):S6. doi: 10.1186/1471-2202-9-S2-S6

Vingtdeux, V., Giliberto, L., Zhao, H., Chandakkar, P., Wu, Q., Simon, J. E., et al. (2010). AMP-activated protein kinase signaling activation by resveratrol modulates amyloid-beta peptide metabolism. J. Biol. Chem. 285, 9100-9113. doi: 10.1074/jbc.M109.060061

Vrhovšek, U., Eder, R., and Wendelin, S. (1995). The occurrence of trans-resveratrol in Slovenian red and white wines. Acta Aliment 242, 203-212.

Walle, T. (2011). Bioavailability of resveratrol. Ann. N. Y. Acad. Sci. 1215, 9-15. doi: 10.1111/j.1749-6632.2010.05842.x

Walle, T., Hsieh, F., DeLegge, M. H., Oatis, J. E. Jr., and Walle, U. K. (2004). High absorption but very low bioavailability of oral resveratrol in humans. Drug Metab. Dispos. Biol. Fate Chem. 32, 1377-1382. doi: 10.1124/dmd.104.000885

Wang, H., Yang, Y.-J., Qian, H.-Y., Zhang, Q., Xu, H., and Li, J.-J. (2012). Resveratrol in cardiovascular disease: what is known from current research? Heart Fail. Rev. 17, 437-448. doi: 10.1007/s10741-011-9260-4

Wang, J., Ho, L., Zhao, Z., Seror, I., Humala, N., Dickstein, D. L., et al. (2006). Moderate consumption of Cabernet Sauvignon attenuates Abeta neuropathology in a mouse model of Alzheimer's disease. FASEB J. 20, 2313-2320. doi: 10.1096/fj.06-6281com.

Wang, Q., Xu, J., Rottinghaus, G. E., Simonyi, A., Lubahn, D., Sun, G. Y., et al. (2002). Resveratrol protects against global cerebral ischemic injury in gerbils. Brain Res. 958, 439-447. doi: 10.1016/S0006-8993(02)03543-6

Wenzel, E., and Somoza, V. (2005). Metabolism and bioavailability of transresveratrol. Mol. Nutr. Food Res. 49, 472-481. doi: 10.1002/mnfr.200500010.

Wimo, A., Winblad, B., Aguero-Torres, H., and von Strauss, E. (2003). The magnitude of dementia occurrence in the world. Alzheimer Dis. Assoc. Disord. 17, 63-67. doi: 10.1097/00002093-200304000-00002

Wyss-Coray, T., Loike, J. D., Brionne, T. C., Lu, E., Anankov, R., Yan, F., et al. (2003). Adult mouse astrocytes degrade amyloid-beta in vitro and in situ. Nat. Med. 9, 453-457. doi: 10.1038/nm838

Youdim, K. A., Dobbie, M. S., Kuhnle, G., Proteggente, A. R., Abbott, N. J., and Rice-Evans, C. (2003). Interaction between flavonoids and the blood-brain barrier: in vitro studies. J. Neurochem. 85, 180-192. doi: 10.1046/j.1471-4159.2003. 01652.x

Yu, C., Shin, Y. G., Chow, A., Li, Y., Kosmeder, J. W., Lee, Y. S., et al. (2002). Human, rat, and mouse metabolism of resveratrol. Pharm. Res. 19, 1907-1914. doi: 10.1023/A:1021414129280 
Zhang, H., Morgan, B., Potter, B. J., Ma, L., Dellsperger, K. C., Ungvari, Z., et al. (2010). Resveratrol improves left ventricular diastolic relaxation in type 2 diabetes by inhibiting oxidative/nitrative stress: in vivo demonstration with magnetic resonance imaging. Am. J. Physiol. Heart Circ. Physiol. 299, H985-994. doi: 10.1152/ajpheart.00489.2010

Zhang, H., Zhang, J., Ungvari, Z., and Zhang, C. (2009). Resveratrol improves endothelial function: role of TNF $\{$ alpha $\}$ and vascular oxidative stress. Arterioscler. Thromb. Vasc. Biol. 29, 1164-1171. doi: 10.1161/ATVBAHA.109. 187146

Zhang, Y., Song, H., Shang, Z., Chen, A., Huang, D., Zhao, H., et al. (2014). Amino Acid-PEGylated Resveratrol and Its Influence on Solubility and the Controlled Release Behavior. Biol. Pharm. Bull. 37, 785-793. doi: 10.1248/bpb.b1300863

Zhuang, H., Kim, Y.-S., Koehler, R. C., and Doré, S. (2003). Potential mechanism by which resveratrol, a red wine constituent, protects neurons. Ann. N. Y. Acad. Sci. 993, 276-286; discussion 287-288. doi: 10.1111/j.1749-6632.2003.tb07534.x
Conflict of Interest Statement: The authors declare that the research was conducted in the absence of any commercial or financial relationships that could be construed as a potential conflict of interest.

Received: 06 June 2014; accepted: 04 August 2014; published online: 11 September 2014.

Citation: Rege SD, Geetha T, Griffin GD, Broderick TL and Babu JR (2014) Neuroprotective effects of resveratrol in Alzheimer disease pathology. Front. Aging Neurosci. 6:218. doi: 10.3389/fnagi.2014.00218

This article was submitted to the journal Frontiers in Aging Neuroscience.

Copyright (c) 2014 Rege, Geetha, Griffin, Broderick and Babu. This is an openaccess article distributed under the terms of the Creative Commons Attribution License (CC BY). The use, distribution or reproduction in other forums is permitted, provided the original author(s) or licensor are credited and that the original publication in this journal is cited, in accordance with accepted academic practice. No use, distribution or reproduction is permitted which does not comply with these terms. 